\title{
Painful knees and hearing-loss: a rare presentation of meningococcal disease
}

\author{
Vivienne Kahlmann, ${ }^{1}$ Celina Alves, ${ }^{2}$ Johannes Coleman, ${ }^{3}$ Lindy-Anne Korswagen ${ }^{2}$
}

${ }^{1}$ Department of Internal Medicine, Franciscus Gasthuis \& Vlietland, Rotterdam, ZuidHolland, The Netherlands ${ }^{2}$ Department of Rheumatology, Franciscus Gasthuis \& Vlietland, Rotterdam, ZuidHolland, The Netherlands ${ }^{3}$ Department of Medical Microbiology, Franciscus Gasthuis \& Vlietland, Rotterdam, Zuid-Holland, The Netherlands

Correspondence to Vivienne Kahlmann, vivienne. kahlmann@gmail.com

Accepted 13 June 2016

\section{CrossMark}

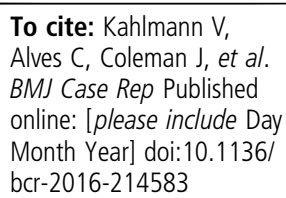

\section{SUMMARY}

A 49-year-old woman with a medical history of rheumatoid arthritis presented to the emergency room, with high fever and painful knees. In addition, she had had a mild headache for several days and some hearing loss over several months. We saw an ill patient with arthritis of both knees, from which purulent fluid was aspirated. Antibiotics were started for septic arthritis of both knees and her condition improved rapidly. However, the headache persisted and the hearing loss worsened. At the time, meningitis was suspected. Initial knee aspiration culture was positive for Neisseria meningitidis. PCR of the cerebrospinal fluid sample also was positive for $N$. meningitidis. The patient was finally diagnosed with bilateral septic gonarthritis secondary to a bacterial meningitis caused by $N$. meningitidis.

\section{BACKGROUND}

The incidence of invasive meningococcal disease (IMD) is < cases per 100000 in North America and Europe, and has declined over the past decades due to effective vaccination programmes. ${ }^{1}$ However, the mortality and morbidity, respectively around $10 \%$ and $18 \%$, remain high and have not improved in the past years. ${ }^{2}$ The most common presentation of IMD is meningitis, and this occurs in $30-60 \%$ of patients. $^{3}$ The typical signs and symptoms of meningitis are: fever, neck stiffness and decreased level of consciousness. These symptoms can be absent in up to two-thirds of patients. ${ }^{4} \mathrm{~A}$ more specific finding for meningococcal disease is petechial rash, but this is only observed in $45-65 \%$ of patients. ${ }^{4}$ However, meningococcal disease can present with various symptoms. ${ }^{5}$ Immunocompromised patients, especially, can present atypically, which may hamper diagnosis. However, early diagnosis and prompt treatment are essential to decrease morbidity and mortality. ${ }^{25}$

\section{CASE PRESENTATION}

A 49-year-old woman with a medical history of rheumatoid arthritis presented to the emergency room, with high fever and painful knees. She had also experienced nausea, vomiting and a mild headache for 3 days. Furthermore, she had experienced hearing loss over several months, which had become worse a few days before presentation. The rheumatoid arthritis was in remission with a combination of methotrexate with folic acid and hydroxychloroquine. Additional medication consisted of salmeterol/fluticasone for asthma, and pantoprazole.

We saw an ill patient with a temperature of $39.2^{\circ} \mathrm{C}$ and a respiratory rate of 24 breaths $/ \mathrm{min}$. Other vital signs were normal. Cardiac, pulmonary and abdominal examinations were normal. She had bilateral arthritis of the knees. A few subtle purpura were visible on the left foot and elbow. We were concerned about the neck stiffness at presentation. The consulting neurologist found no signs of meningism and therefore did not perform a lumbar puncture. Purulent fluid was aspired from both knees. Blood drawn at presentation showed: C reactive protein $349 \mathrm{mg} / \mathrm{L}$, leucocytes $34.9 \times 10^{9}$, haemoglobin $7.0 \mathrm{mmol} / \mathrm{L}$ and mean corpuscular volume $92 \mathrm{fL}$, and renal and liver tests were normal. Chest X-ray and urinary tests were normal, excluding urinary tract infection and pneumonia as a cause of this patient's fever.

The most likely diagnosis at the time seemed to be septic arthritis of both knees. The patient was admitted and treated with cefuroxime, and a single dose of gentamicin, intravenously. The methotrexate and hydroxychloroquine were discontinued. The fever disappeared, inflammatory markers decreased and the patient's condition improved rapidly. However, she still had a mild headache and the hearing loss worsened. A hearing test showed hearing loss of $60 \mathrm{db}$ in low-frequency tones, which could not be explained by the use of hydroxychloroquine. Meningitis was reconsidered. Around this time, cultures of the knee aspirate were shown positive for Neisseria meningitidis. A lumbar puncture showed an increased leucocyte count. Cerebrospinal fluid (CSF) culture remained sterile, which may be explained by the prior antibiotic treatment. However, PCR analysis of the CSF detected DNA of N. meningitidis. The isolate of the knee aspirate was fully susceptible to penicillin (minimal inhibitory concentration, $M I C=0.032 \mathrm{mg} / \mathrm{L})$, cefotaxime $(\mathrm{MIC} \leq 0.002 \mathrm{mg} / \mathrm{L})$ and ciprofloxacin $(\mathrm{MIC}=0.004 \mathrm{mg} / \mathrm{L})$.

\section{OUTCOME AND FOLLOW-UP}

The patient finally was diagnosed with septic arthritis secondary to bacterial meningitis caused by N. meningitidis. Antibiotic treatment was changed from cefuroxime to ceftriaxone intravenously and after 10 days to oral ciprofloxacin. The ciprofloxacin was continued for 10 days. The patient was discharged after 10 days of hospitalisation. A few weeks later, she visited the outpatient clinic. The hearing impairment resolved to the pre-existing level of mild hearing loss and no other symptoms remained.

\section{DISCUSSION}

This case report describes the clinical course of a patient with disseminated meningococcal disease. 
The clinical spectrum of meningococcal disease is broad and consists of: meningitis, septicaemia, meningitis in combination with septicaemia, chronic meningococcal infection and focal meningococcal infections (such as isolated pneumonia, conjunctivitis, pericarditis, myocarditis and arthritis). ${ }^{3}$ Arthritis due to N. meningitidis is a less-known presentation of meningococcal disease and is described in about $2-12 \%$ of cases. ${ }^{6-8}$ The arthritis can be septic secondary to meningococcal bacteraemia or can be reactive due to immune complex precipitations in the affected joint. ${ }^{9}$ The presentation can be monoarticular or polyarticular. Large joints are most commonly affected, mainly the knee or ankle. Treatment for septic arthritis consists of antibiotic therapy and joint aspiration. ${ }^{6} 8$ When immune complexmediated reactive arthritis is suspected, treatment with corticosteroids can/may be indicated. ${ }^{6}$

A relatively common complication of IMD is hearing loss, and this occurs in $3.3 \%$ of adult patients. ${ }^{2}$ It is more frequently seen-about $8 \%$-in patients with meningococcal meningitis. ${ }^{4}$ Hearing loss as an initial symptom of meningococcal disease is rare. Only one case report described a presentation similar to that in our case. ${ }^{10}$

Another complicating factor in diagnosing our patient correctly was her rheumatoid arthritis, and possibly also her antirheumatic medication. Rheumatoid arthritis is associated with increased infection rates and mortality from infections, which may be related to the disease itself, or to medication sideeffects. ${ }^{11} 12$ Our patient used methotrexate and hydroxychloroquine for rheumatoid arthritis. There is no clear evidence whether the use of disease-modifying antirheumatic drugs (DMARDs) such as methotrexate and hydroxychloroquine is associated with a higher risk of infections. As far as we know, it is not known whether the use of methotrexate is associated with a higher risk of bacterial meningococcal infection. ${ }^{11} 12$

Treatment of IMD consists of antibiotics and supportive therapy. Antibiotics should be given within 1 hour after presentation if IMD is suspected. ${ }^{2} 5$ Current guidelines advise antibiotic treatment for 5-7 days in case of meningococcal meningitis or sepsis. ${ }^{5}{ }^{13} 14$ In general, septic arthritis is treated with antibiotics for 4-6 weeks, although in arthritis with Neisseria gonorrhoea, treatment duration is only 7 days. ${ }^{15}$ Optimal duration of antibiotic treatment in case of meningococcal arthritis is not known. Our patient was treated with antibiotics empirically for 20 days, taking into account the clinical improvement of her symptoms.

The guidelines for antibiotic treatment vary slightly between different countries, depending on the antibiotic resistance profile. In general, the preferred antibiotic treatment is either penicillin, ceftriaxone or cefotaxime. ${ }^{5}{ }^{13}{ }^{14}$ Penicillin resistance is common and ciprofloxacin resistance is described as well. ${ }^{16} 17$ The first choice according to the Dutch guidelines is penicillin $\mathrm{G}$ intravenously, or in case of penicillin resistance, ceftriaxone or cefotaxime. ${ }^{14}$ Recently, a new guideline in the UK was published in which it is recommended to start treatment with ceftriaxone or cefotaxime in all patients with suspected meningitis or meningococcal sepsis. ${ }^{13}$

Despite advancement in outcome due to improved treatment and vaccination programmes, mortality and morbidity of IMD remain high. Early recognition of patients who may develop severe IMD is important to improve prognosis. Recently, in a large prospective cohort study on children and adults, the most significant risk factor for mortality was septic shock. ${ }^{2}$ Another major risk factor was older age. Common complications in adults were: deafness, skin scarring, motor neurological deficits and renal dysfunction. Important risk factors for developing complications were septic shock and thrombocytopaenia. Less complications were seen if the administration of antibiotic occurred before admission. ${ }^{2}$

This case report illustrates the various presentations of IMD. IMD can progress rapidly and can be fatal. Therefore recognition and prompt treatment is crucial.

\section{Learning points}

- The spectrum of meningococcal disease is broad and the presentation is often non-specific. Diagnosis should also be considered when a patient presents with a focal infection, such as arthritis, or less frequent symptoms such as hearing loss.

- Meningococcal disease is a severe condition that can be fatal. Early recognition and prompt treatment with appropriate antibiotics improve the prognosis remarkably.

- In immunocompromised patients, performing more invasive diagnostic tests such as a lumbar puncture should be considered even when the suspicion of meningitis is low.

Contributors VK drafted the case report and the other authors revised the case report critically for important intellectual content.

Competing interests None declared.

\section{Patient consent Obtained.}

Provenance and peer review Not commissioned; externally peer reviewed.

\section{REFERENCES}

1 Halperin SA, Bettinger JA, Greenwood B, et al. The changing and dynamic epidemiology of meningococcal disease. Vaccine 2012;30:B26-36.

2 Sadarangani M, Scheifele DW, Halperin SA, et al. Outcomes of invasive meningococcal disease in adults and children in Canada between 2002 and 2011: a prospective cohort study. Clin Infect Dis 2015;60:e27-35.

3 Pace D, Pollard AJ. Meningococcal disease: clinical presentation and sequelae. Vaccine 2012;30:B3-9.

4 Heckenberg SGB, de Gans J, Brouwer MC, et al. Clinical features, outcome, and meningococcal genotype in 258 adults with meningococcal meningitis: a prospective cohort study. Medicine (Baltimore) 2008;87:185-92.

5 Campsall PA, Laupland KB, Niven DJ. Severe meningococcal infection a review of epidemiology, diagnosis and management. Crit Care Clin 2013;29:393-409.

6 Cabellos C, Nolla JM, Verdaguer R, et al. Arthritis related to systemic meningococcal disease: 34 years' experience. Eur J Clin Microbiol Infect Dis 2012;31:2661-6.

7 Weisfelt M, van de Beek D, Spanjaard L, et al. Arthritis in adults with community-acquired bacterial meningitis: a prospective cohort study. BMC Infect Dis 2006;6:64.

8 Schaad UB. Arthritis in disease due to Neisseria meningitidis. Rev Infect Dis 1980;2:880-8

9 Goedvolk CA, von Rosenstiel IA, Bos AP. Immune complex associated complications in the subacute phase of meningococcal disease: incidence and literature review. Arch Dis Child 2003;88:927-30.

10 Abad VC, Ng B, Somasunderam M. Hearing loss as an initial symptom of meningococcal meningitis. Arch Neurol 1983;40:451-3.

11 Lacaille D, Guh DP, Abrahamowicz M, et al. Use of nonbiologic disease-modifying antirheumatic drugs and risk of infection in patients with rheumatoid arthritis. Arthritis Rheum 2008;59:1074-81.

12 Salliot C, van der Heijde D. Long-term safety of methotrexate monotherapy in patients with rheumatoid arthritis: a systematic literature search. Ann Rheum Dis 2009;68:1100-4.

13 McGill F, Heyderman RS, Michael BD, et al. The UK joint specialist societies guideline on the diagnosis and management of acute meningitis and meningococcal sepsis in immunocompetent adults. J Infect 2016;72:405-38.

14 Guidelines on antibacterial therapy of patients with bacterial central nervous system infections [internet]. Nijmegen: Dutch Working Party on Antibiotic Policy, 2012 (cited 18 Mar 2016). http://www.swab.nl/swab/cms3.nsf/uploads/ FE54A057082AA54CC1257A2B00293B1D/\$FILE/SWAB_CNSguideline_\% 20June12.pdf 
15 Tabidze IL, Nicholson TF, Mikati T, et al. Adherence to centers for disease control and prevention gonococcal treatment guidelines among Chicago health care providers, 2011-2012. Sex Transm Dis 2015;42:422-8.

16 Bertrand S, Carion F, Wintjens R, et al. Evolutionary changes in antimicrobial resistance of invasive Neisseria meningitidis isolates in Belgium from 2000 to 2010: increasing prevalence of penicillin nonsusceptibility. Antimicrob Agents Chemother 2012;56:2268-72.

17 Wu HM, Harcourt BH, Hatcher $\mathrm{CP}$, et al. Emergence of ciprofloxacin-resistant Neisseria meningitidis in North America. N Engl J Med 2009;360: 886-92.

Copyright 2016 BMJ Publishing Group. All rights reserved. For permission to reuse any of this content visit

http://group.bmj.com/group/rights-licensing/permissions.

BMJ Case Report Fellows may re-use this article for personal use and teaching without any further permission.

Become a Fellow of BMJ Case Reports today and you can:

- Submit as many cases as you like

- Enjoy fast sympathetic peer review and rapid publication of accepted articles

- Access all the published articles

- Re-use any of the published material for personal use and teaching without further permission

For information on Institutional Fellowships contact consortiasales@bmjgroup.com

Visit casereports.bmj.com for more articles like this and to become a Fellow 